\title{
You Can't Have It All: The Experience of Academic Hospitalists During Pregnancy, Parental Leave, and Return to Work
}

\author{
Emily Gottenborg, MD* , Anna Maw, MD, Li-Kheng Ngov, MD, Marisha Burden, MD, \\ Anastasiya Ponomaryova, BS, Christine D. Jones, MD, MS
}

Department of Medicine, Division of Hospital Medicine, University of Colorado, Denver, Colorado.

BACKGROUND: The United States lags behind most other countries regarding the support for working mothers and parental leave. Data are limited to describe the experience of female hospital medicine physicians during pregnancy, parental leave, and their return to work in academic hospital medicine.

METHODS: We conducted a qualitative descriptive study including interviews with 10 female academic hospitalists chosen from institutions across the country that are represented in Society of Hospital Medicine (SHM) Committees. Interview guides were based on the following domains: experience in pregnancy, parental leave, and return to work. Interviews were recorded, transcribed verbatim, and analyzed using a general inductive approach to theme analysis using the ATLAS.ti software (Scientific Software Development $\mathrm{GmbH}$, Berlin, Germany).

PRIMARY OUTCOME: Women in hospital medicine experience the following six common challenges in their experience as new parents, each of which has the potential to impact their career trajectory, wellness, and are associated with areas for institutional improvement: (1) access to paid parental leave, (2) physical challenges, (3) breastfeeding, (4) career opportunities, (5) colleague responses, and (6) empathy in patient care. Journal of Hospital Medicine 2018;13:836-839. ( $) 2018$ Society of Hospital Medicine

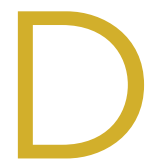

espite recent advances made in medicine, gender-based disparities persist..$^{1-3}$ In particular, women with children have barriers to career advancement and show evidence of slower career advancement. ${ }^{1,2}$ Multiple challenges for working women experiencing motherhood have been described. In academic medicine in the United States, women have limited access to paid parental leave.4-6 For women who choose to breastfeed, there is limited time, space, and support available for breastfeeding. ${ }^{7}$ Furthermore, sleep deprivation in the postpartum period significantly impacts the ability to function at work. ${ }^{8}$

Hospital medicine is a unique specialty as it comprises $47 \%$ women, $80 \%$ of whom are aged less than 40 years, suggesting that a large portion are women of childbearing age. ${ }^{9}$ The field poses known challenges to this population, including shift work, atypical schedules, and unpredictable hours. We conducted a descriptive qualitative study to improve our understanding of the experience of female academic hospitalists who have experienced pregnancy, parental leave, and the re-

\footnotetext{
*Address for correspondence: Emily Gottenborg, MD, Assistant Professor, Department of Medicine, Division of Hospital Medicine, University of Colorado, 12401 E. 17th Avenue, Leprino Building, Room 480; Aurora, Colorado, 80045; Telephone: 720- 848-4289; Fax: 720-848 4290; E-mail: Emily.gottenborg@ ucdenver.edu
}

Additional Supporting Information may be found in the online version of this article.

Received: April 1, 2018; Revised: June 15, 2018; Accepted: July 19, 2018

๑) 2018 Society of Hospital Medicine DOI 10.12788/jhm.3076 turn to work as faculty. Our goal was to both explore the challenges to undergoing this experience and discover solutions to support female academic hospitalists.

\section{METHODS}

\section{Study Design}

We conducted a qualitative descriptive study of female hospitalists recruited from academic institutions represented in Society of Hospital Medicine (SHM) committees. Interviews were conducted between November 2017 and February 2018. Participants completed an informed consent and a demographic survey prior to the interview. Each interview lasted approximately 30 minutes; discussions were recorded on digital records and transcribed verbatim. This protocol was reviewed and granted exemption by the Institutional Review Board at the University of Colorado.

\section{Population}

We recruited participants from a selection of hospital medicine groups nationally, chosen from SHM committee representation. A purposeful snowball approach was used to identify hospitalists from representative programs and seek their recommendation for hospitalists from other targeted programs. Ten hospitalists were approached by e-mail to determine their interest in participation, and all of them agreed to participate. Each participant experienced new parenthood within the last seven years.

\section{Framework}

We constructed our interview to represent the following timeline associated with having children as it pertains to a hospi- 
talist position: pregnancy, parental leave, and the return to work. The interview guide was structured to invoke the positive aspects, challenges, and solutions within each domain (Appendix 1).

\section{Analysis}

Codes were inductively developed from the interview data by a team of three board-certified internal medicine physicians (E.G., A.M., and C.J.), one of whom had prior training and experience with qualitative interviews and analysis (C.J.). Among the coders, two (E.G. and A.M.) conducted the semistructured interviews. Code disparities were reconciled by team consensus, where the primary coder facilitated the discussions. Themes were developed inductively from the codes, and the analysis was completed using a team-based iterative approach that was facilitated using ATLAS.ti. ${ }^{10}$ Thematic saturation was achieved. This study was approved by the Colorado Multiple Institutional Review Board.

\section{RESULTS}

The demographics and the characteristics of the hospital medicine group are shown in Table 1. Although we asked questions about both the positive and challenging aspects of the experience of parenthood, the interviews tended to focus more on the challenges faced and on areas for optimization.

\section{Paid Parental leave}

Most of the participants described inadequate paid parental leave, with minimal transparency in the processes for ensuring time off following the birth of their child, resulting in "haggling" with bosses, human resources, and the administrative staff. Rarely was a formal parental leave policy in place. Once a parental leave plan was established, several women reported the financial burden associated with a leave that was partially, or fully, unpaid.

"All of my leave was unpaid. .. managed to finagle short-term disability into paying for it... the system was otherwise set up to screw me financially."

For the three women who did experience sufficient paid parental leave, they recognized the financial and emotional benefit and suggested that further optimization would include a prebirth schedule to account for the physical challenges and potential complications.

\section{Physical Challenges}

All of the women described significant physical challenges when working during pregnancy, resulting in limited bandwidth for additional academic activities outside of direct clinical care responsibilities.

"Exhaustion that hits you in your pregnancy and then you have to round. I used to lie on the floor of my office, take a little nap, wake up, write some notes, go home, take another nap, wake up, write some more notes."

Upon return to work, women reported additional physical challenges related to sleep deprivation, impacting their pro-
TABLE 1. Characteristics of Participating Physicians, Female Academic Hospitalists

\begin{tabular}{lcc}
\hline & & N (\%) \\
\hline Clinical FTE & $0.7-1.0$ & $6(60)$ \\
& $0.4-0.7$ & $2(20)$ \\
Years in Practice & $<0.4$ & $2(20)$ \\
& $>7$ & $3(30)$ \\
& $5-7$ & $3(30)$ \\
Academic Title & $<5$ & $4(40)$ \\
& Instructor & \\
Group Characteristics & Associant Professor Professor & $10(100)$ \\
Members & & \\
& $>50$ & \\
& $30-50$ & $7(70)$ \\
Region & $<30$ & $1(10)$ \\
& Northeast & $2(20)$ \\
& Southeast & $2(10)$ \\
& Midwest & $2(20)$ \\
& Mountain West & $2(20)$ \\
& Pacific Northwest & $3(30)$
\end{tabular}

ductivity with academic work and emotional well-being. "I came back from maternity leave and I was sleep-deprived and exhausted, I didn't have the energy. All of these great projects that I had started or dreamed of

... dwindled and died on the vine."

Solutions suggested by the participants included creation of a flexible schedule with a ramp-up and ramp-down period around the birth.

\section{Breastfeeding}

The majority of participants in this study encountered several challenges associated with a shared goal of breastfeeding according to evidence-based guidelines. ${ }^{11}$ Designated pumping areas were often inconveniently located and not conducive to multitasking.

"It's two chairs that are behind a curtain in a women's locker room in the basement of the hospital, that are tiny and gross. No computers, so I felt like I was wasting time."

One hospitalist described carving out time for pumping in her office while multitasking with clinical work.

"I would get to work, set up, and pump while chart reviewing. Then I would go and see people... and come back to my office and pump and write a few notes. And go out and see more patients, and then pump and write a few more notes. And then pump, and then go home. I was like a cow."

Women highlighted the barriers that could be optimized such as creating time in the clinical schedule for pumping, a physical space to breastfeed or pump, and accessible milk storage facilities. 
TABLE 2. Solutions for the Challenges Reported Related to Pregnancy, Parental Leave, and Return to Work, with Representative Quotes

\begin{tabular}{|c|c|}
\hline Theme & Solution \\
\hline Lack of Paid Parental Leave & $\begin{array}{l}\text { "Two separate leaves: one for pregnancy complications, which you can invoke if you have a complication, and one for post-baby arrival, so you are not trying } \\
\text { to conserve post-baby time by working with complications." }\end{array}$ \\
\hline Physical Challenges & $\begin{array}{l}\text { "Planning the schedule so that when someone comes back they can have either a ramp-up with reduced complement of shifts, or structure shifts so that you're } \\
\text { not working a long block in a row." }\end{array}$ \\
\hline \multirow[t]{2}{*}{ Breastfeeding Barriers } & Addressing access to space, time, and milk storage to alleviate the challenges noted in the quote: \\
\hline & $\begin{array}{l}\text { "Pumping every 3-4 hours: stopping what you're doing, finding an empty room to pump, finding a place to store your milk, then going back to work, three times } \\
\text { per shift, for the next } 9 \text { months of your life, was hell." }\end{array}$ \\
\hline Career Opportunities & $\begin{array}{l}\text { "My boss... is pretty conscientious about, 'let's save that opportunity for her, when she comes back, it would be most appropriate for her.' So I don't feel like } \\
\text { I got left over for any opportunity." }\end{array}$ \\
\hline \multirow[t]{2}{*}{ Colleague Responses } & $\begin{array}{l}\text { "The role-modeling and getting permission to prioritize my children. I feel like I am surrounded by a group of people that really understands the need to balance } \\
\text { work and family and support each other." }\end{array}$ \\
\hline & "The Physician Moms Group on Facebook, it's amazing it's now 70,000 people... But the power of that support, I wish it had started earlier." \\
\hline Empathy Gain & $\begin{array}{l}\text { "I'm just more sensitive to people's lives outside the hospital, so, you know, when it's difficult for a family member to get there because they have three other kids } \\
\text { they are taking care of or, somebody that says they are leaving AMA, but it's because they have a sick kid at home. I just have a better context for that." }\end{array}$ \\
\hline
\end{tabular}

\section{Career Opportunities}

When asked about the impact of parental leave on career opportunities, a few of the women described a phenomenon of no longer being asked to participate or being left out of prior projects.

"People didn't want to offer you things or give you things because they realize you're having this transition in your life. Not out of animosity, but out of courtesy that they don't want to fill up your place even more. Her plate is full; we are not going to ask her to do anything extra."

However, two women specifically reported a supportive environment without a loss of opportunities, often referenced as a boss who "saved" projects for their return.

\section{Colleague Responses}

One participant used the term "microaggressions," to describe passive aggressions encountered by their colleagues or leadership.

"(A colleague) was diagnosed with pre-eclampsia, and very urgently had to deliver and couldn't cover a week of shifts... She was asked initially to find her own coverage... Not treating (pregnancy) similar to other serious illnesses is what I would term a microaggression."

Yet, women in our study also reported positive responses from colleagues and the importance of support networks of physician mothers (Table 2).

\section{Empathy in Patient Care}

Finally, the experience of motherhood impacted all of the women as physicians, described as increased empathy, patience, and understanding of difficult family situations.

"I'm just more sensitive to people's lives outside the hospital, so, you know, when it's difficult for a family member to get there because they have three other kids they are taking care of or, somebody that says they are leaving AMA, but it's because they have a sick kid at home. I just have a better context for that."

\section{DISCUSSION}

Gender disparities persist in both internal medicine and hospital medicine. Providers in this descriptive qualitative study suggested that the following factors contribute: lack of paid parental leave and the associated financial penalties, loss of career opportunities, the physical challenges associated with pregnancy, decreasing productivity, and the amount of time and effort involved in breastfeeding. However, the participants also shared valuable ideas for future solutions to relieve the challenges imposed on working physician mothers (Table 2).

\section{Breaking the Glass Ceiling}

Participants noted the importance of a paid leave policy that encompasses not only maternity leave but also a flexible scheduling period before and after the leave to account for the challenges of pregnancy and new motherhood. Paid parental leave is rare in academic settings, but studies from other industries show that when women take paid leave, they are more likely to remain in the workforce 9-12 months afterward, work more weekly hours, and feel more loyal to their organization. ${ }^{12,13}$ In the rare instance when negotiations around leave violate local policy or the law, women should be encouraged to seek guidance from their human resources department.

\section{Me Too: Building Solidarity}

Women in our study reported the value of a supportive workplace in easing their transition into motherhood. Specifically, they noted that a supportive boss who protected their career opportunities prevented momentum loss in their career trajectory. Access to mutual supports such as the Physicians Mom Group, a well-established Facebook group comprising more 
than 70,000 women, was referenced as a meaningful way to share joys and tribulations related to balancing a career as a physician and motherhood. Growth of similar support systems within institutions will further support this experience.

\section{Time's Up: The Promotion Clock}

Women in our study described a prolonged period of diminished productivity related to having children, coinciding with a set time to promotion in academics. Flexible promotion schedules may impact women's ability to successfully undergo promotion.

\section{FUTURE DIRECTION}

The aim of this study was to represent a shared set of experiences of female academic hospitalists who participated; therefore, the results may not be generalizable beyond this group. Due to the use of a purposeful snowball approach, there was a

\section{References}

1. Association of American Medical Colleges. The State of Women in Academic Medicine: The pipeline and pathways to leadership, 2013-2014. https://www. hopkinsmedicine.org/women_science_medicine/_pdfs/The\%20State\%20 of\%20Women\%20in\%20Academic\%20Medicine\%202013-2014\%20FINAL. pdf. Accessed February 26, 2018.

2. Carr $\mathrm{PL}$, Ash $\mathrm{AS}$, Friedman $\mathrm{RH}$, et al. Relation of family responsibilities and gender to the productivity and career satisfaction of medical faculty. Ann Int Med. 1998;129(7):532-538. doi: 10.7326/0003-4819-129-7-199810010-00004.

3. Burden M, Frank MG, Keniston A, et al. Gender disparities for academic hospitalists. J Hosp Med. 2015;10(8):481-485. doi:10.1002/jhm.2340.

4. Bristol MN, Abbuhl S, Cappola AR, Sonnad SS. Work-life policies for faculty at the top ten medical schools. J Women's Health. 2008;17(8):1311-1320. doi: 10.1089/jwh.2007.0682.

5. Welch JL, Wiehe SE, Palmer-Smith V, Dankoski ME. Flexibility in faculty worklife policies at medical schools in the big ten conference. J Women's Health. 2011;20(5):725-732. doi: 10.1089/jwh.2010.2553.

6. Riano NS, Linos E, Accurso EC, et al. Paid family and childbearing leave policies at top US medical schools. JAMA. 2018;319(6):611-614. doi: 10.1001/ jama.2017.19519.

7. Arthur CR, Saenz RB, Replogle WH. The employment-related breastfeeding potential for selection bias. Future research may include comparing the experience of women at institutions that offer paid leave versus those that do not and the impact on retention, promotion, and well-being.

\section{CONCLUSION}

Women in hospital medicine encounter several challenges to having children, but they are also motivated to provide solutions. Efforts to improve the institutional and cultural landscape to better support women physicians with children are critical to prevent attrition of women and ensure equitable academic promotion and achievement of leadership positions.

Disclosures: The authors have no conflicts of interest to report.

Author Contributions: Each author was involved in the creation of the study protocol, data collection and analysis, and creation of the manuscript.

decisions of physician mothers. J Miss State Med Assoc. 2003;44(12):383-387.

8. Filtness AJ, MacKenzie J, Armstrong K. Longitudinal change in sleep and daytime sleepiness in postpartum women. PLoS ONE. 2014;9(7):e103513. doi: 10.1371/journal.pone.0103513.

9. Reid MB, Misky GJ, Harrison RA, Sharpe B, Auerbach A, Glasheen JJ. Mentorship, productivity, and promotion among academic hospitalists. J Gen Intern Med. 2012;27(1):23-27. doi: 10.1007/s11606-011-1892-5.

10. Jones J, Nowels CT, Sudore R, Ahluwalia S, Bekelman DB. The future as a series of transitions: qualitative study of heart failure patients and their informal caregivers. J Gen Intern Med. 2015;30(2):176-182. doi: 10.1007/s11606-014-3085-5.

11. American Academy of Pediatrics. Breastfeeding and the use of human milk. Pediatrics. 2012;129(3):e827-e841. doi: 10.1542/peds.2011-3552.

12. Houser, L, Vartanian, T. Pay matters: the positive economic impact of paid family Leave for families, businesses and the public. Center for Women and Work at Rutgers. January, 2012. http://go.nationalpartnership.org/site/ DocServer/Pay_Matters_Positive_Economic_Impacts_of_Paid_Fam ily_L.pd$f$ ?doclD=9681. Accessed February 26, 2018.

13. Rossin-Slater M, Ruhm C, Waldfogel J. The effects of California's paid family leave program on mothers' leave-taking and subsequent labor market outcomes. J Policy Anal Manage. 2013;32(2):224-245. doi: 10.1002/pam.21676. 